\title{
Management of antiplatelet therapy resistance in cardiac surgery
}

\author{
Hrvoje Gasparovic, MD, PhD, Mate Petricevic, MD, and Bojan Biocina, MD, PhD
}

The role of coronary artery bypass grafting (CABG) in the management of complex coronary artery disease has been validated through an unparalleled level of scrutiny. Improvement in patient outcomes currently relies on continued refinements of the surgical technique and modulation of adjuvant pharmacotherapy. Postoperative antiplatelet therapy (APT) is paramount in maintaining the revascularization benefit. However, individual variability to APT results in unpredictable platelet inhibition. Currently available platelet function tests (PFTs) dichotomize patients into "responders" and "nonresponders" on the basis of arbitrarily defined cutoff points. It is not surprising that the incidence of APT resistance across the spectrum of PFTs is widely discrepant, underscoring the fact that single pathway descriptors of platelet aggregation fail to portray the complexity of the process. Thrombosis is the principal mode of failure of saphenous vein grafts (SVGs) in the early postoperative period. ${ }^{1}$ Reports on the increased incidence of SVG failure in patients experiencing antiplatelet agent resistance underscore the importance of recognizing this entity and intervening in a timely fashion. This review summarizes the various assay-dependent definitions of APT resistance, with their respective rates of occurrence. The clinical impact of on-therapy high residual platelet reactivity (hRPR) in the cardiac surgical arena is discussed. Finally, guidelines on individual tailoring of APT in patients found to retain high on-therapy platelet reactivity are suggested.

\section{MATERIALS AND METHODS}

The PubMed database was searched using the following subject terms: platelet function testing, antiplatelet, aspirin, clopidogrel, resistance, and cardiac surgery. Reference lists of identified publications were analyzed for additional linking studies. Priority was given to cohort studies and reviews.

\section{Definition of Antiplatelet Therapy Resistance}

Aspirin is the most commonly used antiplatelet agent after CABG. Its use is associated with a $40 \%$ reduction in bypass graft occlusions, ${ }^{2}$ with the benefit being most evident in SVGs. ${ }^{3,4}$ The incidences

From the Department of Cardiac Surgery, Clinical Hospital Center Zagreb, University of Zagreb, Zagreb, Croatia.

Disclosures: Authors have nothing to disclose with regard to commercial support. Drs Gasparovic and Petricevic contributed equally to the manuscript.

Received for publication July 14, 2013; revisions received Sept 24, 2013; accepted for publication Oct 6, 2013; available ahead of print Dec 13, 2013

Address for reprints: Hrvoje Gasparovic, MD, PhD, Department of Cardiac Surgery,

Clinical Hospital Center Zagreb, Kispaticeva 12, 10000 Zagreb, Croatia (E-mail:

hgasparovic@gmail.com).

J Thorac Cardiovasc Surg 2014;147:855-62

$0022-5223 / \$ 36.00$

Copyright (c) 2014 by The American Association for Thoracic Surgery

http://dx.doi.org/10.1016/j.jtcvs.2013.10.008 of SVG occlusions within the first year, when the impact of thrombosis is greatest, range from $7.4 \%$ to $26 \% .^{5-7}$ This angiographic outcome is accompanied by a $20 \%$ to $30 \%$ reoccurrence of angina and a $5.9 \%$ need for repeat revascularization within the first year. ${ }^{9}$ The current guidelines on postoperative APT recommend the initiation of 100 to $325 \mathrm{mg}$ of aspirin within 6 hours of surgery. ${ }^{10}$ In patients unable to take aspirin, $75 \mathrm{mg}$ of clopidogrel is the suggested alternative. $^{10}$

The importance of prompt postoperative institution of aspirin is underscored by the fact that starting aspirin on the third postoperative day or later is unlikely to reflect favorably on graft patency. ${ }^{11,12}$ However, the one-sizefits-all recommendation for perioperative APT in the current guidelines disregards the individual response variability.

The term aspirin resistance denotes the drug's inability to effectively suppress cyclooxygenase-1-dependent thromboxane A2 (TxA2) production. Aspirin's failure to act on its pharmacologic target originates from variable enteral absorption, cyclooxygenase 1 gene mutations, drug-drug interactions, patient noncompliance, accelerated postcardiopulmonary bypass platelet turnover, and TxA2-independent platelet activation pathways. ${ }^{13,14}$ The prevalence of aspirin resistance varies widely in the literature because of variable platelet agonists used in testing and different aspirin-related platelet function descriptors (Table 1).

Clopidogrel is an inactive prodrug that undergoes extensive conversion into its active metabolite by the hepatic cytochrome P450 (CYP) 3A4 enzyme. ${ }^{15}$ It irreversibly inhibits the $\mathrm{P}_{2} \mathrm{Y}_{12}$ adenosine diphosphate (ADP) receptor, which is one of the pivotal routes of platelet activation. Difficulties in elucidating the true incidence of clopidogrel resistance parallel those for aspirin, because it is also assay-dependent. $\mathrm{P}_{2} \mathrm{Y}_{12}$ receptor, $A B C B 1$, and $C Y P 2 C 19$ genetic polymorphisms affect clopidogrel pharmacodynamics. ${ }^{15,16}$ Strategies moving beyond phenotype-directed into genotype-directed tailoring of APT have become available, but they currently lack validation in larger trials. ${ }^{16}$ Clopidogrel's metabolic activation also is altered by medications acting as substrates for CYP3A4. Significant reductions in the clopidogrel-induced inhibition of platelet aggregation have been noted in patients using atorvastatin and proton pump inhibitors. Conflicting data on the clinical relevance of such interactions have been published. ${ }^{17-22}$ Antiplatelet agent response is best perceived as a continuous variable. However, the efficacy of APT may be assessed in relation to cutoff points discriminating between "resistance" and "response," or by measuring the on-therapy percent platelet inhibition and comparing it with values obtained before APT. The drawback of the latter strategy is that it is affected by variability in baseline platelet reactivity. In contrast, strict cutoff values are invariably arbitrarily defined but do allow for comparing outcomes in a binary model. The definition of antiplatelet agent resistance remains a moving target. Lordkipanidze and colleagues ${ }^{23}$ compared 6 different PFTs to determine the prevalence of aspirin resistance and found a poor mutual correlation between individual tests. A succinct overview of the cutoff points defining antiplatelet agent resistance using different PFTs is presented in Table 1. Distinguishing between cardiac surgical patients in whom APT resistance is permanent from those in whom it may be a temporary phenomenon may hold practical value. The distinction between the 2 can be made by comparing preoperative with postoperative PFT results. In patients found to have on-therapy hRPR preoperatively, the resistance is likely a permanent one. Conversely, adequate preoperative platelet inhibition followed by early postoperative hRPR may suggest that the phenomenon is transient in nature. Our group has shown a consistent increase in postoperative platelet reactivity evaluated with aggregometry in comparison with 


$\begin{array}{ll}\text { Abbreviations and Acronyms } \\ \text { ADP } & =\text { adenosine diphosphate } \\ \text { APT } & =\text { antiplatelet therapy } \\ \text { BOCLA-Plan }= & \text { BOchum CLopidogrel and } \\ & \text { Aspirin Plan } \\ \text { CABG } & =\text { coronary artery bypass grafting } \\ \text { CI } & =\text { confidence interval } \\ \text { CYP } & =\text { cytochrome P450 } \\ \text { dAPT } & =\text { dual antiplatelet therapy } \\ \text { HR } & =\text { hazard ratio } \\ \text { hRPR } & =\text { high residual platelet reactivity } \\ \text { PFT } & =\text { platelet function test } \\ \text { SVG } & =\text { saphenous vein graft } \\ \text { TxA2 } & =\text { thromboxane A2 }\end{array}$

preoperative values, ${ }^{24}$ which is suggestive of heightened platelet reactivity induced by surgery.

\section{Clinical Impact of Antiplatelet Therapy Resistance}

Aspirin-resistant TxA2 synthesis has been found to elevate the risk of stroke, myocardial infarction, and cardiovascular death in patients with cardiovascular disease. ${ }^{25}$ A graded increase in the aforementioned risk was observed with each increasing quartile of urinary 11-dehydro thromboxane B2, which is a metabolic surrogate of TxA2 activity. ${ }^{25}$

Investigators in the prevention of Coronary arteRY bypaSS occlusion After off-pump procedures (CRYSSA) trial noted an alarming correlation between graft occlusion and APT resistance (relative risk, 3.6; 95\% confidence interval $[\mathrm{CI}], 2.5-6.9 ; P<.001) .{ }^{5}$ Conversely, synergistic aspirin- and clopidogrel-induced platelet inhibition was found to predict SVG patency (relative risk, $5.1 ; 95 \% \mathrm{CI}, 1.4-16.3 ; P<.01){ }^{5}$ The link between SVG occlusion and platelet hyperreactivity on aspirin was reported as the secondary objective of the Reduction in Graft Occlusion Rates study.$^{13}$ A higher incidence of early SVG occlusion was found in patients taking aspirin who had increased levels of urinary 11-dehydro thromboxane B2 and sheardependent platelet activation. ${ }^{13}$

Clopidogrel resistance also has been found to be clinically significant by several investigators. Adverse cardiovascular events adjudicated at 6 months were found to be more common in clopidogrel-resistant patients undergoing primary angioplasty for acute myocardial infarction. ${ }^{26}$ High platelet reactivity to ADP on dual antiplatelet therapy (dAPT) increased cardiovascular mortality (hazard ratio [HR], 2.55; 95\% CI, 1.08-6.07; $P$ $<.034)$ and nonfatal myocardial infarction (HR, 3.36; 95\% CI, 1.49$7.58 ; P<.004)$ at 12 -month follow-up in a similar clinical setting. ${ }^{27} \mathrm{~A}$ more comprehensive overview of the clinical impact of APT resistance is provided in Table 1. Clopidogrel cessation is advocated in anticipation of elective cardiac surgery to minimize perioperative blood loss. ${ }^{10}$ One must recognize that this is potentially hazardous because it may induce a rebound prothrombotic and proinflammatory state. ${ }^{28}$ Mahla and colleagues ${ }^{29}$ proved that clopidogrel can be continued safely up to surgery provided that residual on-therapy platelet reactivity evaluated by thromboelastography remained high. Analogously, Di Dedda and colleagues ${ }^{30}$ recently documented that $32 \%$ of patients scheduled for cardiac surgery retained hRPR on clopidogrel. These observations again add credence to APT monitoring, because it may directly influence the preoperative discontinuation of clopidogrel and possibly lead to a revision of current guidelines.

\section{Management Options for Antiplatelet Agent Resistance}

With the problem of antiplatelet agent resistance lacking a clear outline and definition, it is not surprising that guidelines for its management remain to be formed. Although a large proportion of the evidence examining the impact of APT resistance is observational in nature or comes from the nonsurgical arena, there are 2 prospective randomized trials that will provide more data on the augmentation of APT in drug-resistant patients undergoing CABG. ${ }^{31,32}$ The former ${ }^{31}$ has reached the data-analysis stage, whereas the latter ${ }^{32}$ is still recruiting patients. Coronary bypass grafts may be especially vulnerable in the immediate postoperative period, and there is growing evidence that APT resistance should not be ignored. The first step in individualized tailoring of platelet inhibition should be PFTs at approximately 7 days of APT initiation (Figure 1). Once hRPR is recognized, extrinsic factors should be ruled out, such as patient noncompliance, drug interactions or suboptimal glucose, and cholesterol regulation.

Because antiplatelet drug resistance may be a temporary manifestation, one course of action is to reevaluate the drug effect without changing the current platelet inhibition regimen. Within 7 days, both aspirin and unbolused clopidogrel reach steady-state drug levels. Therefore, we recommend repeating PFTs 7 days after any PFT result that is outside the desired therapeutic window.

A significant proportion of patients recognized as clopidogrel resistant 24 hours after its institution were found to respond to the drug when reevaluated at 30 days. ${ }^{33,34}$ Likewise, the proportion of patients undergoing $\mathrm{CABG}$ who were found to be aspirin resistant is inversely proportional to the time elapsed between its assessment and the procedure itself. ${ }^{35,36}$ This point again brings into focus the importance of isolating patients with permanent postoperative APT resistance from those with transient postoperative APT resistance. In the event that a follow-up evaluation of platelet function shows persistence of low responsiveness, different lines of management should be explored.

An effective approach to APT resistance is to increase the drug dose. In diabetic patients found to be hyporesponsive to $100 \mathrm{mg}$ of aspirin, increasing the dose to $300 \mathrm{mg}$ led to superior platelet inhibition (platelet function analyzer closure time increased from $170 \pm 45$ seconds to 229 \pm 75 seconds, $P<.001) .{ }^{37}$ Increased loading and maintenance doses of clopidogrel also have been found to surmount the resistance to lower-dose therapy. ${ }^{15,38}$ Doubling the dose of clopidogrel in patients found to be nonresponders to $75 \mathrm{mg}$ effectively inhibited platelets in $60 \%$ of patients. ${ }^{39}$ Neubauer and colleagues ${ }^{38}$ reduced the incidence of clopidogrel resistance from $23.6 \%$ to $5 \%$ by modification of the administered dose based on an aggregometer-guided algorithm. However, the conversion of nonresponders using this strategy remains unpredictable, which emphasizes the need for reevaluating the effectiveness of platelet inhibition after the implemented dose change. ${ }^{39}$ The BOchum CLopidogrel and Aspirin Plan (BOCLA-Plan) incorporating a "test and treat" strategy effectively eliminated aspirin resistance by dose modification and subsequent PFT. ${ }^{40}$ Of the $19.4 \%$ patients found to be low-responsive to $100 \mathrm{mg}$ of aspirin, $94.6 \%$ were converted to responders by increasing the dose to $300 \mathrm{mg}^{40}$ The remaining $5.4 \%$ received effective platelet inhibition by further increasing the dose to $500 \mathrm{mg}$ of aspirin. ${ }^{40}$ However, it is important to acknowledge the potential of high-dose aspirin to worsen endothelialmediated arterial dilatation. ${ }^{41}$ A similar protocol was implemented for the $30.8 \%$ of patients found to be resistant to $75 \mathrm{mg}$ of clopidogrel. Increasing the dose to $150 \mathrm{mg}$, in line with the predefined BOCLA-Plan, induced effective platelet inhibition in $69 \%$ of previously resistant patients. $^{40}$

Finally, an attractive solution to the problem of hRPR on 1 platelet inhibitor is to add a different agent to induce an additive effect or to substitute the original drug altogether. The different mechanisms of platelet inhibition targeted by aspirin and thienopyridines allow for accumulation of their individual anti-aggregational effects. Mannacio and colleagues ${ }^{5}$ showed that dAPT effectively overcame single drug resistances, with a subsequent 
reduction in SVG occlusion (7.4\% vs $13.1 \% ; P=.04)$. Patients randomized to dAPT in the CRYSSA trial experienced similar rates of both minor $(2 \%$ vs $1.3 \%, P=.5)$ and major bleeding episodes $(1.3 \%$ vs $1.3 \%, P=$ 1.0) in comparison with the aspirin-monotherapy group. ${ }^{5}$ The safety of dAPT was corroborated by similar chest tube outputs in both treatment arms $(115 \pm 80 \mathrm{~mL}$ in the aspirin group vs $125 \pm 70 \mathrm{~mL}$ in the dAPT group; $P=.2) .{ }^{5}$ The administration of clopidogrel on the background of aspirin therapy in the early postoperative period did not increase the rate of reexploration or transfusion in a study by Chan and colleagues. ${ }^{42}$ Commonly used protocols include starting dAPT when chest tube drainage has been $50 \mathrm{~mL}$ or less for 2 hours. ${ }^{5,42}$ However, we would recommend exercising caution in restarting clopidogrel in patients taking preoperative dAPT with documented profound ADP inhibition. Our group has documented that preoperative Multiplate ASPI test (Dynabyte Gmbh, Munich, Germany) values less than 20 area under the curve units and ADP test less than 73 area under the curve units predicted higher postoperative chest tube output. ${ }^{43}$

Although clopidogrel and aspirin account for the most commonly used combination of antiplatelet drugs, the potential advantages of novel agents may lead to a future revision of that paradigm. New-generation $\mathrm{P}_{2} \mathrm{Y}_{12}$ inhibitors are less susceptible to genetic polymorphisms.

Clopidogrel requires 2 CYP-mediated oxidative steps to reach its active metabolite, whereas prasugrel requires only 1 . It initiates faster and more potent platelet inhibition, with less interpatient response variability than its predecessor. ${ }^{44}$ The Trial to Assess Improvement in Therapeutic Outcomes by Optimizing Platelet Inhibition with Prasugrel-Thrombolysis In Myocardial Infarction 38 demonstrated prasugrel's superiority over clopidogrel in the reduction of major adverse cardiovascular events in patients with acute coronary syndromes (HR, $0.81 ; 95 \% \mathrm{CI}, 0.73-0.90 ; P<.001) .{ }^{45}$ The reduction in major adverse cardiovascular events was offset by an increased risk of bleeding. ${ }^{45}$ The post hoc analysis of patients in the prasugrel treatment arm who underwent CABG mirrored the general study population's increased bleeding risk. ${ }^{46}$ However, overall mortality was significantly lower in the prasugrel than in the clopidogrel $\mathrm{CABG}$ cohort despite comparable risk profiles (adjusted odds ratio, $0.26 ; 95 \% \mathrm{CI}, 0.08-0.85 ; P=.025) .{ }^{46}$ A potential problem in interpreting these results is that all-cause mortality was as high as $8.67 \%$ in the clopidogrel cohort, which had a mean European System for Cardiac Operative Risk Evaluation of only $3.6 \pm 3.2 .^{46}$ This caveat is amplified by the fact that European System for Cardiac Operative Risk Evaluation may even overestimate CABG mortality. ${ }^{46,47}$ Nevertheless, prasugrel's highly effective platelet inhibition and low incidence of nonresponsiveness make it a suitable candidate for patients found to be resistant to prior APT. In the BOCLA-Plan, patients found to be clopidogrel resistant to even an augmented dosing regimen benefited from the addition of prasugrel in achieving the targeted antiplatelet effect. ${ }^{40}$

Ticagrelor is absorbed as an active agent and is therefore unaffected by the idiosyncrasies of intrinsic biotransformation. Its prompt and reversible $\mathrm{P}_{2} \mathrm{Y}_{12}$ inhibition was responsible for a significant reduction in adverse events in its direct comparison with clopidogrel in the Study of Platelet Inhibition and Patient Outcomes (HR, 0.84; 95\% CI, 0.77-0.92; $P<.001){ }^{48}$ The ticagrelor cohort had a $22 \%$ relative reduction in mortality. ${ }^{48}$ The incidence of bleeding in the CABG subgroup was not affected by ticagrelor, presumably because of the reversible nature of its $\mathrm{P}_{2} \mathrm{Y}_{12}$ inhibition. ${ }^{48}$ It has already been shown to be useful in upgrading APT in patients found to be clopidogrel hyporesponders. ${ }^{49}$ In the Response to Ticagrelor in Clopidogrel Nonresponders and Responders and Effect of Switching Therapies trial, it has provided more uniform and enhanced platelet inhibition in comparison with clopidogrel, practically eliminating on-therapy hRPR. ${ }^{49}$

Prompt induction of platelet inhibition can be achieved with cangrelor. It is a direct-acting $\mathrm{P}_{2} \mathrm{Y}_{12}$ inhibitor that immediately suppresses platelet aggregation. ${ }^{50}$ Its effect is quickly reversible on the drug's discontinuation. ${ }^{50}$ Cangrelor's intravenous mode of administration overcomes the variability in enteral absorption and bioavailability seen in patients with acute hemodynamic compromise. ${ }^{51}$ In addition, its short half-life (3-5 minutes) allows for precise bridging of APT in patients scheduled for elective cardiac surgery, without increasing the risk of major bleeding. ${ }^{52}$ Although the pharmacokinetic properties of cangrelor make it unsuitable for long-term management of APT resistance, its potential applicability in the acute perioperative setting warrants mentioning.

Redundancy and parallel activation pathways characterize clot formation. The role of thrombin in the process of thrombosis goes beyond the generation of fibrin, because it is a potent platelet agonist. Its platelet activation effects are mediated by protease-activated receptor $1 .{ }^{53}$ Vorapaxar is a novel antiplatelet agent that inhibits platelet aggregability by targeting protease-activated receptor 1. In the Thrombin Receptor Antagonist in Secondary Prevention of Atherothrombotic Ischemic Events-Thrombolysis in Myocardial Infarction 50 trial, vorapaxar reduced the incidence of death or adverse ischemic events over placebo on the background of standard therapy (HR, 0.87; 95\% CI, 0.80-0.94; $P<.001) .{ }^{53}$ It increased the risk of bleeding, including intracranial hemorrhage. ${ }^{53}$ Exploiting alternative routes of platelet inhibition may be reasonable in patients found to be resistant to the more commonly targeted platelet receptors.

Because the activation of clopidogrel is dependent on CYP3A4, it stands to reason that pharmacologic induction of this enzyme's metabolic activity may convert clopidogrel nonresponders into responders. ${ }^{54} \mathrm{Co}$ administration of rifampin and clopidogrel has been used to explore and prove this concept in healthy volunteers. ${ }^{54}$ Whether this approach is of any value in the cardiac surgical population is as of yet unknown.

\section{DISCUSSION}

Despite the absence of an all-encompassing method for defining antiplatelet response, there is sufficient evidence to support wider dissemination of tools designed to quantify on-therapy platelet reactivity. Strategies using PFTs to guide transfusion therapy, reduce bleeding, and tailor APT are gaining momentum in the modern cardiac surgical practice..$^{55,56}$ Platelet aggregability after cardiac surgery is inconsistent over the early postoperative period. Its unpredictable nature stems from the integration of several opposing influences. The effects of postoperative platelet depletion and iatrogenic platelet inhibition are counterbalanced by accelerated postcardiopulmonary bypass platelet turnover. Therefore, longitudinal follow-up of platelet reactivity is a useful adjunct to standard postoperative protocols aiming to achieve optimal patient outcomes.

APT resistance may offset the benefits of surgical myocardial revascularization. Point-of-care PFTs provide timely information regarding residual platelet reactivity. Unfortunately, individual PFTs provide data that are not always reciprocated by other tests. This brings into focus the need for standardization and clinical validation of each test. It is unlikely that different PFTs will ever provide completely interchangeable results because of the large variability of platelet activation pathways that are being tested. Recognizing the impact of APT resistance should serve as an impetus for the definition of its management algorithms. Although APT resistance after cardiac surgery may be a transient phenomenon, it occurs during the period when graft patency is most vulnerable. dAPT or incremental drug increases in conjunction with regular PFTs are useful in overcoming this problem. The contemporary expansion 
TABLE 1. Antiplatelet therapy resistance: Assay-specific definitions, prevalence, and clinical impact

\begin{tabular}{|c|c|c|c|c|c|}
\hline \multirow[b]{2}{*}{ Study } & \multirow[b]{2}{*}{ Patient population } & \multicolumn{3}{|c|}{ Aspirin resistance } & \multirow{2}{*}{$\begin{array}{c}\text { Clopidogrel resistance } \\
\text { Incidence }\end{array}$} \\
\hline & & Incidence & Platelet function test & $\begin{array}{c}\text { POC } \\
\text { turnaround time }\end{array}$ & \\
\hline Mannacio and colleagues ${ }^{5}$ & $\operatorname{OPCAB}(\mathrm{n}=300)$ & $32.6 \%$ ( $5 \mathrm{~d}$ after treatment initiation) & $\begin{array}{l}\text { VerifyNow Aspirin (Accumetrics Inc, } \\
\text { San Diego, Calif) }\end{array}$ & $<10$ min & $\begin{array}{l}22 \% *(5 \mathrm{~d} \text { after } \\
\quad \text { treatment initiation })\end{array}$ \\
\hline Sambu and colleagues ${ }^{57}$ & Stent thrombosis $(\mathrm{n}=39)$ & $28 \%$ (at inclusion) & $\begin{array}{l}\text { Short TEG (Haemonetics Corp, } \\
\text { Braintree, Mass) }\end{array}$ & $15 \mathrm{~min}$ & $67 \% \dagger$ (at inclusion) \\
\hline \multirow[t]{4}{*}{ Gluckman and colleagues ${ }^{13}$} & $\operatorname{CABG}(\mathrm{n}=229)$ & $\begin{array}{l}5 \% \text { (at } 3 \text { d postoperatively) } ; 0.9 \% \text { (at } \\
\quad 6 \text { mo postoperatively) }\end{array}$ & $\begin{array}{l}\text { AA-induced platelet aggregometry } \\
\text { (Chrono-Log Corp, Havertown, Pa) }\end{array}$ & $7 \mathrm{~min}$ & Not reported \\
\hline & & $\begin{array}{l}16 \% \text { (at } 3 \mathrm{~d} \text { postoperatively); } 10 \% \text { (at } \\
\quad 6 \text { mo postoperatively) }\end{array}$ & VerifyNow Aspirin & $<10 \min$ & \\
\hline & & $\begin{array}{l}64 \% \text { (at } 3 \mathrm{~d} \text { postoperatively); } 12 \% \text { (at } \\
\quad 6 \text { mo postoperatively) }\end{array}$ & PFA-100 CEPI & $5-8 \mathrm{~min}$ & \\
\hline & & $\begin{array}{l}73 \% \text { (at } 3 \mathrm{~d} \text { postoperatively); } 31 \% \text { (at } \\
\quad 6 \text { mo postoperatively) }\end{array}$ & $\mathrm{UTxB}_{2}$ & N/A & \\
\hline Petricevic and colleagues ${ }^{24}$ & $\mathrm{CABG}(\mathrm{n}=99)$ & $\begin{array}{l}31.3 \% \text { (preoperatively); } 46.5 \% \text { (at } \\
\quad 4 \mathrm{~d} \text { postoperatively) }\end{array}$ & $\begin{array}{l}\text { Multiplate ASPI test (Dynabyte Gmbh, } \\
\text { Munich, Germany) }\end{array}$ & $9 \min$ & Not reported \\
\hline Preisman and colleagues ${ }^{58}$ & CABG $(\mathrm{n}=59)$ & $44 \%$ (preoperatively) & $\begin{array}{l}\text { TEG platelet mapping (Haemoscope } \\
\text { Corp, Niles, Ill) }\end{array}$ & Up to $1 \mathrm{~h}$ & $85 \%$ (preoperatively) \\
\hline \multirow{6}{*}{$\begin{array}{l}\text { Lordkipanidze and } \\
\text { colleagues }^{23}\end{array}$} & Stable coronary & $4 \%$ & LTA (AA) & N/A & Not reported \\
\hline & disease $(n=201)$ & $10.3 \%-51.7 \%$ & LTA (ADP) & N/A & \\
\hline & & $18 \%$ & $\begin{array}{l}\text { Whole blood aggregometry (Chrono- } \\
\text { Log Corp) }\end{array}$ & $7 \mathrm{~min}$ & \\
\hline & & $59.5 \%$ & PFA-100 & $5-8 \mathrm{~min}$ & \\
\hline & & $6.7 \%$ & VerifyNow Aspirin & $<10 \mathrm{~min}$ & \\
\hline & & $22.9 \%$ & $\mathrm{UTxB}_{2}$ concentration & N/A & \\
\hline Kempfert and colleagues ${ }^{59}$ & $\mathrm{CABG} / \mathrm{OPCAB}(\mathrm{n}=59)$ & $\begin{array}{l}28.8 \% \text { (preoperatively) } ; 49.2 \% \text { (at } \\
\quad 5 \text { d postoperatively) }\end{array}$ & $\begin{array}{l}\text { Turbidimetric aggregometry (PAP-4; } \\
\text { Moelab, Berlin, Germany) }\end{array}$ & N/A & Not reported \\
\hline Bednar and colleagues ${ }^{60}$ & CABG/OPCAB $(\mathrm{n}=80)$ & Not reported & $\begin{array}{l}\text { PAP-4 Platelet Aggregation Profiler } \\
\text { (BioData Corp, Horsham, Pa) }\end{array}$ & N/A & Not reported \\
\hline \multirow[t]{2}{*}{ Poston and colleagues ${ }^{61}$} & OPCAB $(\mathrm{n}=76)$ & $\begin{array}{c}3 \% \text { preoperatively; } 13.2 \% \\
\text { postoperatively (at } \\
3 \mathrm{~d} \text { postoperatively) }\end{array}$ & $\begin{array}{l}\text { TEG platelet mapping (Haemoscope } \\
\text { Corp) }\end{array}$ & Up to $1 \mathrm{~h}$ & Not reported \\
\hline & & & $\begin{array}{l}\text { Whole blood aggregometry (Chrono- } \\
\text { Log Corp) }\end{array}$ & $7 \mathrm{~min}$ & Not reported \\
\hline Di Dedda and colleagues ${ }^{30}$ & Cardiac surgery $(n=344)$ & Not reported & Not reported & N/A & $32 \%$ preoperatively \\
\hline
\end{tabular}

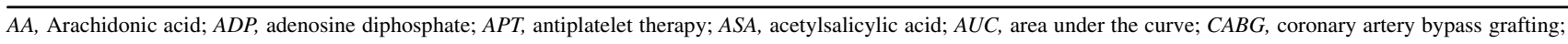
$C A D P$, collagen/adenosine-5'-diphosphate closure time; $C E P I$, collagen and epinephrine; $C I$, confidence interval; $L T A$, light transmittance aggregometry; MAadp, maximal amplitude (clot strength assessed after addition of adenosine diphosphate); $N / A$, not available; $O P C A B$, off-pump coronary artery bypass; $\% M A_{A S A}$, percentage change effect of acetylsalicylic acid on maximum amplitude in arachidonic acid activated samples; $P O C$, point-of-care; $P F A$, platelet function analyzer; $R R$, relative risk; $S D$, standard deviation; $S V G$, saphenous vein graft; $T E G$, thromboelastography; $T X A_{2}$, thromboxane $\mathrm{A} 2 ; U T x B_{2}$, urinary 11-dehydro thromboxane $\mathrm{B} 2 ; W B A$, whole blood aggregometry; $P A P$, platelet aggregation profiler; $A S P I$, platelet function test using arachidonic acid as an agonist.*In CRYSSA, $12.6 \%$ of patients were resistant to both aspirin and clopidogrel. $\dagger$ In the Clopidogrel Resistance in Stent Thrombosis study, $26 \%$ of patients were resistant to both aspirin and clopidogrel. $\ddagger$ Multiple WBA provides 3 parameters: velocity, area under the curve, and percent platelet inhibition. Area under the curve provides the greatest diagnostic yield. ${ }^{62}$ Several studies report cutoff values delineating aspirin resistance using Multiplate. ${ }^{63-65} \S$ Cutoff values were adjusted for number of days after preoperative clopidogrel discontinuation and expressed as percentage of the normal range value of ADP test as indicated by manufacturer (53-122 U [area under the curve]). $\|$ Gurbel and colleagues ${ }^{66}$ investigated the prognostic value of thromboelastography (MAadp) in assessment of ischemic events among patients undergoing percutaneous coronary intervention. MAadp $>47 \mathrm{~mm}$ was found to be the best predictor of ischemic events (receiver operating area under the curve, $0.84 ; 95 \% \mathrm{CI}, 0.78-0.89 ; P<.0001)$. 
TABLE 1. Continued

\begin{tabular}{|c|c|c|c|c|}
\hline \multicolumn{2}{|c|}{ Clopidogrel resistance } & \multicolumn{2}{|c|}{ Cutoff value for APT resistance } & \multirow[b]{2}{*}{ Outcome } \\
\hline Platelet function test & POC turnaround time & Aspirin & Clopidogrel & \\
\hline VerifyNow $\mathrm{P}_{2} \mathrm{Y}_{12}$ & $<10 \min$ & Aspirin reaction units $>550$ & $\begin{array}{l}\mathrm{P}_{2} \mathrm{Y}_{12} \text { resistance units }>230 \text { and } \\
\text { platelet inhibition }>30 \%\end{array}$ & $\begin{array}{l}\text { APT resistance predicted graft } \\
\text { occlusion (RR, 3.6; 95\% CI, 2.5- } \\
\quad 6.9 ; P<.001)\end{array}$ \\
\hline Short TEG (Haemonetics Corp) & $15 \mathrm{~min}$ & $<50 \%$ TEG platelet inhibition & $<30 \%$ TEG platelet inhibition & $\begin{array}{l}\text { Inclusion criterion was stent } \\
\text { thrombosis }\end{array}$ \\
\hline \multirow[t]{4}{*}{ Not reported } & N/A & $>1 \mathrm{Ohm}$ & Not reported & $\begin{array}{l}\text { No correlation between APT resistance } \\
\text { and SVG patency }\end{array}$ \\
\hline & & Aspirin reaction units $\geq 550$ & Not reported & $\begin{array}{l}\text { No correlation between APT resistance } \\
\text { and SVG patency }\end{array}$ \\
\hline & & CEPI clotting time $\leq 193 \mathrm{~s}$ & Not reported & $\begin{array}{l}\text { SVG occlusion was more prevalent in } \\
\text { subjects with CADP clotting time } \\
\leq 88 \text { s (at } 6 \text { mo); no correlation with } \\
\text { CEPI }\end{array}$ \\
\hline & & $\mathrm{UTxB}_{2} \geq 400 \mathrm{pg} / \mathrm{mg}$ creatinine & Not reported & $\begin{array}{l}\text { ASA-insensitive } \mathrm{TXA}_{2} \text { generation, } \\
\text { measured by } \mathrm{UTxB}_{2} \text {, predicted } \\
\text { SVG thrombosis }\end{array}$ \\
\hline Not reported & N/A & $\geq 30 \mathrm{AUC} \neq$ & Not reported & Not reported \\
\hline $\begin{array}{l}\text { TEG platelet mapping (Haemoscope } \\
\text { Corp) }\end{array}$ & Up to $1 \mathrm{~h}$ & AA-induced platelet activation $>50 \%$ & $\begin{array}{l}\text { ADP-induced platelet activation } \\
\quad>50 \%\end{array}$ & $\begin{array}{l}\text { MAadp }<42.5 \mathrm{~mm} \text { predicted increased } \\
\text { postoperative bleeding }\end{array}$ \\
\hline Not reported & N/A & $\begin{array}{l}\text { Residual platelet aggregation }>20 \% \\
\text { Residual ADP-induced platelet } \\
\quad \text { aggregation }>70 \% \\
>3 \text { Ohms } \\
\text { Aperture closure time }<193 \mathrm{sec} \\
\text { Aspirin reaction units } \geq 550 \\
\geq 67.9 \mathrm{ng} / \mathrm{mmol} \text { of creatinine }\end{array}$ & Not reported & Not reported \\
\hline Not reported & N/A & $\begin{array}{l}\text { Platelet aggregation }>30 \% \text { despite } \\
\text { in vitro addition of } 25 \mu \mathrm{mol} / \mathrm{L} \text { ASA } \\
\text { to exclude noncompliance }\end{array}$ & Not reported & $\begin{array}{l}\text { Three deaths occurred after 12-mo } \\
\text { follow-up. All were perioperatively } \\
\text { found to be aspirin resistant. }\end{array}$ \\
\hline Not reported & N/A & $\begin{array}{l}\text { Platelet aggregation was assessed as } \\
\text { continuous variable without cutoff } \\
\text { for clopidogrel resistance. }\end{array}$ & Not reported & $\begin{array}{l}\text { Nonsignificant relationship between } \\
\text { platelet aggregation studies and } \\
\text { chest tube discharge in } 24 \mathrm{~h} \text { was } \\
\text { noted. }\end{array}$ \\
\hline Not reported & N/A & $>1$ SD above the normal value & Not reported $\|$ & $\begin{array}{l}\% \mathrm{MA}_{\mathrm{ASA}}(\mathrm{TEG}) \text { higher in patients } \\
\text { with occluded grafts }(55 \pm 22 \text { vs } 22 \\
\pm 17, P=.05) \text {; WBA } \% \mathrm{Ohm} 6 \mathrm{~min} \\
\text { low vs high dose }(69 \pm 25 \text { vs } 35 \pm\end{array}$ \\
\hline Not reported & N/A & $>1$ SD above the normal value & Not reported & $\begin{array}{l}20, P=.05 \text { ) higher in patients with } \\
\text { occluded grafts. }\end{array}$ \\
\hline ADP test Multiplate (Dynabyte Gmbh) & $9 \mathrm{~min}$ & Not reported & $\begin{array}{l}\S>60 \% \text { of lower limit of normal range } \\
\quad \text { (last clopidogrel dose within } 1 \mathrm{~d} \text { ); } \\
\text { ADP test }>32 \mathrm{U} \\
\S>70 \% \text { of lower limit of normal range } \\
\quad \text { (last clopidogrel dose } 2 \mathrm{~d} \text { ); ADP test } \\
>37 \mathrm{U} \\
\S>80 \% \text { of lower limit of normal range } \\
\quad \text { (last clopidogrel dose } 3 \mathrm{~d} \text { before the } \\
\quad \text { test); ADP test }>43 \mathrm{U} \text {. } \\
\S \text { Platelet aggregation within normal } \\
\text { range }(>53 \mathrm{U} \text { ); last dose of } \\
\text { clopidogrel }>4 \mathrm{~d}\end{array}$ & $\begin{array}{l}\text { The last ADP test result before the } \\
\text { operation was significantly } \\
\text { associated }(P=.002) \text { with } \\
\text { postoperative bleeding and the need } \\
\text { for postoperative platelet } \\
\text { concentrate transfusions; } \\
\text { thrombotic events not reported. }\end{array}$ \\
\hline
\end{tabular}




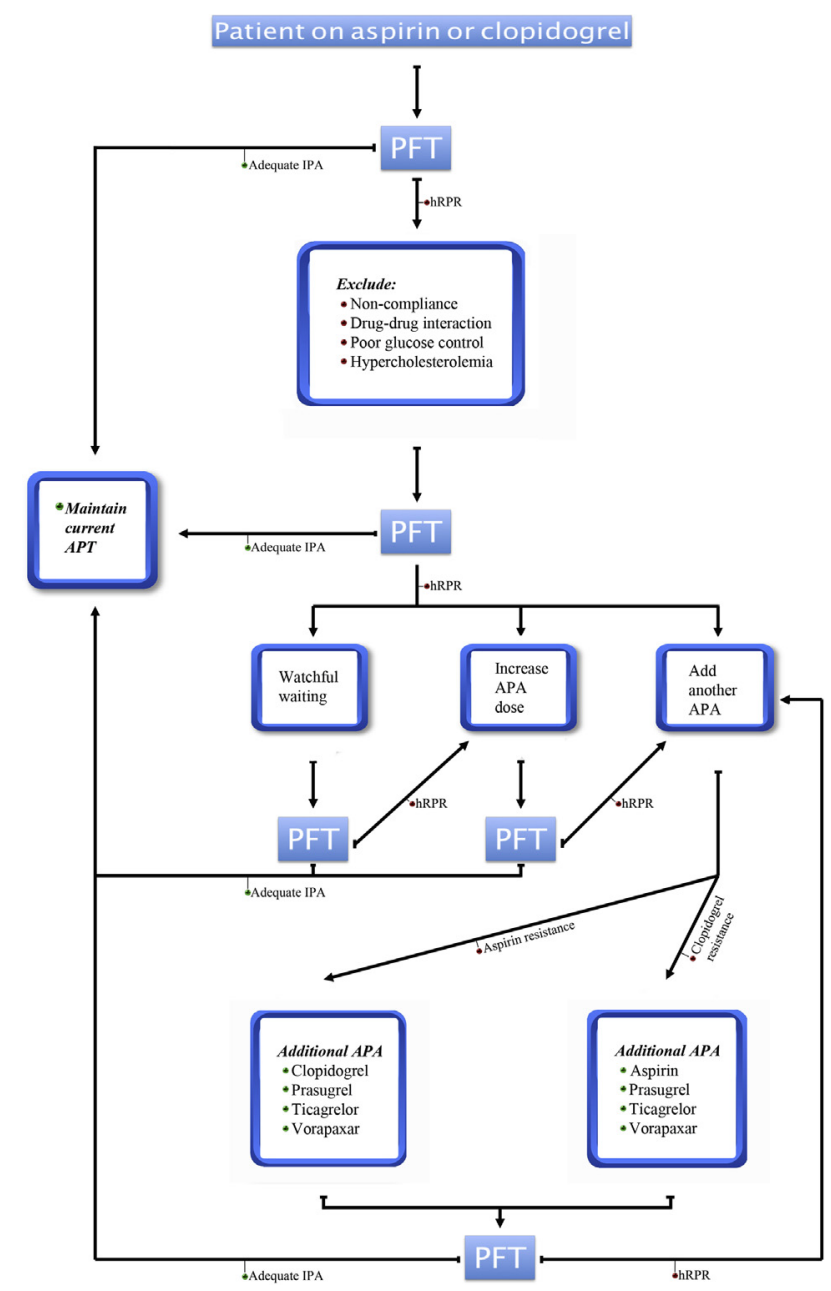

FIGURE 1. Algorithm summarizing management options for patients with documented APT resistance. APA, Antiplatelet agent; $A P T$, antiplatelet therapy; $h R P R$, high residual platelet reactivity; IPA, inhibition of platelet aggregation; $P F T$, platelet function test.

of the antiplatelet drug armamentarium will likely translate into superior outcomes in the clinical domain. The benefits of enhanced platelet inhibition must be balanced against an increased risk of bleeding, which is bound to be its unwanted, yet inevitable, corollary.

\section{CONCLUSIONS}

We advocate the use of point-of-care PFT and tailoring of APT. Prospective accumulation of data on the clinical impact of such strategies is sorely needed for them to become validated on a larger scale.

\section{References}

1. Zimmermann N, Gams E, Hohlfeld T. Aspirin in coronary artery bypass surgery: new aspects of and alternatives for an old antithrombotic agent. Eur J Cardiothorac Surg. 2008;34:93-108.

2. Collaborative overview of randomised trials of antiplatelet therapy-II: maintenance of vascular graft or arterial patency by antiplatelet therapy. Antiplatelet Trialists' Collaboration. BMJ. 1994;308:159-68.
3. Bourassa MG, Fisher LD, Campeau L, Gillespie MJ, McConney M, Lesperance J. Long-term fate of bypass grafts: the Coronary Artery Surgery Study (CASS) and Montreal Heart Institute experiences. Circulation. 1985;72:V71-8.

4. Chesebro JH, Fuster V, Elveback LR, Clements IP, Smith HC, Holmes DR Jr, et al. Effect of dipyridamole and aspirin on late vein-graft patency after coronary bypass operations. N Engl J Med. 1984;310:209-14.

5. Mannacio VA, Di Tommaso L, Antignan A, De Amicis V, Vosa C. Aspirin plus clopidogrel for optimal platelet inhibition following off-pump coronary artery bypass surgery: results from the CRYSSA (prevention of Coronary arteRY bypaSS occlusion After off-pump procedures) randomised study. Heart. 2012; 98:1710-5.

6. Alexander JH, Hafley G, Harrington RA, Peterson ED, Ferguson TB Jr, Lorenz TJ, et al. Efficacy and safety of edifoligide, an E2F transcription factor decoy, for prevention of vein graft failure following coronary artery bypass graft surgery: PREVENT IV: a randomized controlled trial. JAMA. 2005;294:2446-54.

7. Motwani JG, Topol EJ. Aortocoronary saphenous vein graft disease: pathogenesis, predisposition, and prevention. Circulation. 1998;97:916-31.

8. Cameron AA, Davis KB, Rogers WJ. Recurrence of angina after coronary artery bypass surgery: predictors and prognosis (CASS Registry). Coronary Artery Surgery Study. J Am Coll Cardiol. 1995;26:895-9.

9. Serruys PW, Morice MC, Kappetein AP, Colombo A, Holmes DR, Mack MJ, et al. Percutaneous coronary intervention versus coronary-artery bypass grafting for severe coronary artery disease. N Engl J Med. 2009;360:961-72.

10. Dunning J, Versteegh M, Fabbri A, Pavie A, Kolh P, Lockowandt U, et al. Guideline on antiplatelet and anticoagulation management in cardiac surgery. Eur $J$ Cardiothorac Surg. 2008;34:73-92.

11. Lorenz RL, Schacky CV, Weber M, Meister W, Kotzur J, Reichardt B, et al. Improved aortocoronary bypass patency by low-dose aspirin (100 mg daily). Effects on platelet aggregation and thromboxane formation. Lancet. 1984;1: $1261-4$.

12. Sharma GV, Khuri SF, Josa M, Folland ED, Parisi AF. The effect of antiplatelet therapy on saphenous vein coronary artery bypass graft patency. Circulation. 1983;68:II218-21.

13. Gluckman TJ, McLean RC, Schulman SP, Kickler TS, Shapiro EP, Conte JV, et al. Effects of aspirin responsiveness and platelet reactivity on early vein graft thrombosis after coronary artery bypass graft surgery. J Am Coll Cardiol. 2011; 57:1069-77.

14. Zimmermann N, Kienzle P, Weber AA, Winter J, Gams E, Schror K, et al. Aspirin resistance after coronary artery bypass grafting. J Thorac Cardiovasc Surg. 2001; 121:982-4.

15. Gurbel PA, Tantry US. Drug insight: clopidogrel nonresponsiveness. Nat Clin Pract Cardiovasc Med. 2006;3:387-95.

16. Ahn SG, Yoon J, Kim J, Uh Y, Kim KM, Lee JH, et al. Genotype- and phenotypedirected personalization of antiplatelet treatment in patients with non-ST elevation acute coronary syndromes undergoing coronary stenting. Korean Circ J. 2013;43:541-9.

17. Clarke TA, Waskell LA. The metabolism of clopidogrel is catalyzed by human cytochrome P450 3A and is inhibited by atorvastatin. Drug Metab Dispos. 2003;31:53-9.

18. Lau WC, Waskell LA, Watkins PB, Neer CJ, Horowitz K, Hopp AS, et al. Atorvastatin reduces the ability of clopidogrel to inhibit platelet aggregation: a new drug-drug interaction. Circulation. 2003;107:32-7.

19. Serebruany VL, Malinin AI, Callahan KP, Gurbel PA, Steinhubl SR. Statins do not affect platelet inhibition with clopidogrel during coronary stenting. Atherosclerosis. 2001;159:239-41.

20. Saw J, Steinhubl SR, Berger PB, Kereiakes DJ, Serebruany VL, Brennan D, et al. Lack of adverse clopidogrel-atorvastatin clinical interaction from secondary analysis of a randomized, placebo-controlled clopidogrel trial. Circulation. 2003;108:921-4.

21. Dunn SP, Steinhubl SR, Bauer D, Charnigo RJ, Berger PB, Topol EJ. Impact of proton pump inhibitor therapy on the efficacy of clopidogrel in the CAPRIE and CREDO trials. J Am Heart Assoc. 2013;2:e004564.

22. O’Donoghue ML, Braunwald E, Antman EM, Murphy SA, Bates ER, Rozenman Y, et al. Pharmacodynamic effect and clinical efficacy of clopidogrel and prasugrel with or without a proton-pump inhibitor: an analysis of two randomised trials. Lancet. 2009;374:989-97.

23. Lordkipanidze M, Pharand C, Schampaert E, Turgeon J, Palisaitis DA, Diodati JG. A comparison of six major platelet function tests to determine the prevalence of aspirin resistance in patients with stable coronary artery disease. Eur Heart J. 2007;28:1702-8. 
24. Petricevic M, Biocina B, Konosic S, Kopjar T, Kunac N, Gasparovic H. Assessment of platelet function by whole blood impedance aggregometry in coronary artery bypass grafting patients on acetylsalicylic acid treatment may prompt a switch to dual antiplatelet therapy. Heart Vessels. 2013;28:57-65.

25. Eikelboom JW, Hirsh J, Weitz JI, Johnston M, Yi Q, Yusuf S. Aspirin-resistant thromboxane biosynthesis and the risk of myocardial infarction, stroke, or cardiovascular death in patients at high risk for cardiovascular events. Circulation. 2002;105:1650-5.

26. Matetzky S, Shenkman B, Guetta V, Shechter M, Beinart R, Goldenberg I, et al. Clopidogrel resistance is associated with increased risk of recurrent atherothrombotic events in patients with acute myocardial infarction. Circulation. 2004;109: 3171-5.

27. Marcucci R, Gori AM, Paniccia R, Giusti B, Valente S, Giglioli C, et al. Cardiovascular death and nonfatal myocardial infarction in acute coronary syndrome patients receiving coronary stenting are predicted by residual platelet reactivity to ADP detected by a point-of-care assay: a 12-month follow-up. Circulation. 2009;119:237-42.

28. Sambu N, Warner T, Curzen N. Clopidogrel withdrawal: is there a "rebound" phenomenon? Thromb Haemost. 2011;105:211-20.

29. Mahla E, Suarez TA, Bliden KP, Rehak P, Metzler H, Sequeira AJ, et al. Platelet function measurement-based strategy to reduce bleeding and waiting time in clopidogrel-treated patients undergoing coronary artery bypass graft surgery: the timing based on platelet function strategy to reduce clopidogrel-associated bleeding related to CABG (TARGET-CABG) study. Circ Cardiovasc Interv. 2012;5:261-9.

30. Di Dedda U, Ranucci M, Baryshnikova E, Castelvecchio S. Thienopyridines resistance and recovery of platelet function after discontinuation of thienopyridines in cardiac surgery patients. Eur J Cardiothorac Surg. 2013 [Epub ahead of print].

31. Gasparovic H, Petricevic M, Kopjar T, Djuric Z, Svetina L, Biocina B. Dual antiplatelet therapy in patients with aspirin resistance following coronary artery bypass grafting: study protocol for a randomized controlled trial [NCT01159639]. Trials. 2012;13:148.

32. Rafiq S, Johansson PI, Zacho M, Stissing T, Kofoed K, Lilleor NB, et al. Thrombelastographic haemostatic status and antiplatelet therapy after coronary artery bypass surgery (TEG-CABG trial): assessing and monitoring the antithrombotic effect of clopidogrel and aspirin versus aspirin alone in hypercoagulable patients: study protocol for a randomized controlled trial. Trials. 2012;13:48.

33. Gurbel PA, Bliden KP. Durability of platelet inhibition by clopidogrel. Am J Cardiol. 2003;91:1123-5.

34. Gurbel PA, Bliden KP, Hiatt BL, O'Connor CM. Clopidogrel for coronary stenting: response variability, drug resistance, and the effect of pretreatment platelet reactivity. Circulation. 2003;107:2908-13.

35. Golanski J, Chlopicki S, Golanski R, Gresner P, Iwaszkiewicz A, Watala C. Resistance to aspirin in patients after coronary artery bypass grafting is transient: impact on the monitoring of aspirin antiplatelet therapy. Ther Drug Monit. 2005; 27:484-90.

36. Zimmermann N, Kurt M, Winter J, Gams E, Wenzel F, Hohlfeld T. Detection and duration of aspirin resistance after coronary artery bypass grafting. J Thorac Cardiovasc Surg. 2008;135:947-8.

37. Abaci A, Yilmaz Y, Caliskan M, Bayram F, Cetin M, Unal A, et al. Effect of increasing doses of aspirin on platelet function as measured by PFA-100 in patients with diabetes. Thromb Res. 2005;116:465-70.

38. Neubauer H, Lask S, Engelhardt A, Mugge A. How to optimise clopidogrel therapy? Reducing the low-response incidence by aggregometry-guided therapy modification. Thromb Haemost. 2008;99:357-62.

39. Stellbaum C, Ayral Y, Morguet A, Schultheiss HP, Rauch U. Doubling the clopidogrel dose in patients with reduced responsiveness to the standard dose is associated with a limited effectiveness as evaluated by impedance aggregometry. Cardiovasc Revasc Med. 2012;13:159-66.

40. Neubauer H, Kaiser AF, Endres HG, Kruger JC, Engelhardt A, Lask S, et al. Tailored antiplatelet therapy can overcome clopidogrel and aspirin resistancethe BOchum CLopidogrel and Aspirin Plan (BOCLA-Plan) to improve antiplatelet therapy. BMC Med. 2011;9:3.

41. Furuno T, Yamasaki F, Yokoyama T, Sato K, Sato T, Doi Y, et al. Effects of various doses of aspirin on platelet activity and endothelial function. Heart Vessels. 2011;26:267-73.

42. Chan V, Kulik A, Bourke ME, Ressler L, Mesana TG, Ruel M. Clopidogrel is safe early after on- and off-pump coronary artery bypass surgery. J Card Surg. 2007; 22:493-7.
43. Petricevic M, Biocina B, Milicic D, Konosic S, Ivancan V, Milosevic M, et al Bleeding risk assessment using multiple electrode aggregometry in patients following coronary artery bypass surgery. J Thromb Thrombolysis. 2013;35: $31-40$.

44. Yousuf O, Bhatt DL. The evolution of antiplatelet therapy in cardiovascular disease. Nat Rev Cardiol. 2011;8:547-59.

45. Wiviott SD, Braunwald E, McCabe CH, Montalescot G, Ruzyllo W, Gottlieb S, et al. Prasugrel versus clopidogrel in patients with acute coronary syndromes. $N$ Engl J Med. 2007;357:2001-15.

46. Smith PK, Goodnough LT, Levy JH, Poston RS, Short MA, Weerakkody GJ, et al Mortality benefit with prasugrel in the TRITON-TIMI 38 coronary artery bypass grafting cohort: risk-adjusted retrospective data analysis. J Am Coll Cardiol. 2012;60:388-96

47. Mohr FW, Morice MC, Kappetein AP, Feldman TE, Stahle E, Colombo A, et al. Coronary artery bypass graft surgery versus percutaneous coronary intervention in patients with three-vessel disease and left main coronary disease: 5-year follow-up of the randomised, clinical SYNTAX trial. Lancet. 2013;381:629-38.

48. Wallentin L, Becker RC, Budaj A, Cannon CP, Emanuelsson H, Held C, et al. Ticagrelor versus clopidogrel in patients with acute coronary syndromes. $N$ Engl $J$ Med. 2009;361:1045-57.

49. Gurbel PA, Bliden KP, Butler K, Antonino MJ, Wei C, Teng R, et al. Response to ticagrelor in clopidogrel nonresponders and responders and effect of switching therapies: the RESPOND study. Circulation. 2010;121:1188-99.

50. Bhatt DL, Stone GW, Mahaffey KW, Gibson CM, Steg PG, Hamm CW, et al. Effect of platelet inhibition with cangrelor during PCI on ischemic events. $N$ Engl J Med. 2013;368:1303-13.

51. Souckova L, Opatrilova R, Suk P, Cundrle I Jr, Pavlik M, Zvonicek V, et al Impaired bioavailability and antiplatelet effect of high-dose clopidogrel in patients after cardiopulmonary resuscitation (CPR). Eur J Clin Pharmacol. 2013 69:309-17.

52. Angiolillo DJ, Firstenberg MS, Price MJ, Tummala PE, Hutyra M, Welsby IJ, et al. Bridging antiplatelet therapy with cangrelor in patients undergoing cardiac surgery: a randomized controlled trial. JAMA. 2012;307:265-74.

53. Morrow DA, Braunwald E, Bonaca MP, Ameriso SF, Dalby AJ, Fish MP, et al. Vorapaxar in the secondary prevention of atherothrombotic events. $N$ Engl J Med. 2012;366:1404-13.

54. Lau WC, Gurbel PA, Watkins PB, Neer CJ, Hopp AS, Carville DG, et al. Contribution of hepatic cytochrome P450 3A4 metabolic activity to the phenomenon of clopidogrel resistance. Circulation. 2004;109:166-71.

55. Ferraris VA, Brown JR, Despotis GJ, Hammon JW, Reece TB, Saha SP, et al 2011 update to the Society of Thoracic Surgeons and the Society of Cardiovascular Anesthesiologists blood conservation clinical practice guidelines. Ann Thorac Surg. 2011;91:944-82.

56. Ranucci M, Baryshnikova E, Soro G, Ballotta A, De Benedetti D, Conti D. Multiple electrode whole-blood aggregometry and bleeding in cardiac surgery patients receiving thienopyridines. Ann Thorac Surg. 2011;91:123-9.

57. Sambu N, Radhakrishnan A, Dent H, Calver AL, Corbett S, Gray H, et al. Personalised antiplatelet therapy in stent thrombosis: observations from the Clopidogrel Resistance in Stent Thrombosis (CREST) registry. Heart. 2012;98: 706-11.

58. Preisman S, Kogan A, Itzkovsky K, Leikin G, Raanani E. Modified thromboelastography evaluation of platelet dysfunction in patients undergoing coronary artery surgery. Eur J Cardiothorac Surg. 2010;37:1367-74.

59. Kempfert J, Anger K, Rastan A, Krabbes S, Lehmann S, Garbade J, et al. Postoperative development of aspirin resistance following coronary artery bypass. Eur J Clin Invest. 2009;39:769-74.

60. Bednar F, Osmancik P, Vanek T, Mocikova H, Jares M, Straka Z, et al. Platele activity and aspirin efficacy after off-pump compared with on-pump coronary artery bypass surgery: results from the prospective randomized trial PRAGUE 11Coronary Artery Bypass and REactivity of Thrombocytes (CABARET). J Thorac Cardiovasc Surg. 2008;136:1054-60.

61. Poston R, Gu J, Manchio J, Lee A, Brown J, Gammie J, et al. Platelet function tests predict bleeding and thrombotic events after off-pump coronary bypass grafting. Eur J Cardiothorac Surg. 2005;27:584-91.

62. Toth O, Calatzis A, Penz S, Losonczy H, Siess W. Multiple electrode aggregometry: a new device to measure platelet aggregation in whole blood. Thromb Haemost. 2006;96:781-8

63. Petricevic M, Biocina B, Konosic S, Kopjar T, Milosevic M, Gasparovic H. Definition of acetylsalicylic acid resistance using multiple electrode aggregometry in 
patients following coronary artery bypass grafting. In: Forum THS, ed. 21st World Congress World Society of Cardio-Thoracic Surgeons Vol 14. Berlin, Germany: Abstract Book; 2011. 70-1.

64. Skoric B, Milicic D, Lovric D, Gornik I, Skoric KN, Sertic J. Initial patency of the infarct-related artery in patients with acute ST elevation myocardial infarction is related to platelet response to aspirin. Int J Cardiol. 2010;140: 356-8.
65. Jambor C, Weber CF, Gerhardt K, Dietrich W, Spannagl M, Heindl B, et al. Whole blood multiple electrode aggregometry is a reliable point-of-care test of aspirin-induced platelet dysfunction. Anesth Analg. 2009;109:25-31.

66. Gurbel PA, Bliden KP, Navickas IA, Mahla E, Dichiara J, Suarez TA, et al. Adenosine diphosphate-induced platelet-fibrin clot strength: a new thrombelastographic indicator of long-term poststenting ischemic events. Am Heart J. 2010; 160:346-54. 